\title{
From News Receiver to News Produser-The New Relationship between Journalists and Audience in Web 2.0
}

\author{
Tai-Li Wang \\ Graduate Institute of Journalism, National Taiwan University, Taiwan \\ Email: tailiw@ntu.edu.tw
}

Received 16 March 2016; accepted 31 May 2016; published 3 June 2016

Copyright (C) 2016 by author and Scientific Research Publishing Inc.

This work is licensed under the Creative Commons Attribution-NonCommercial International License (CC BY-NC). http://creativecommons.org/licenses/by-nc/4.0/

(c) (i) (9) Open Access

\begin{abstract}
The development of Web 2.0 culture has made social media important instruments for transforming the traditional one-way news production and reception process into a mode of collaborative and interactive journalism. This paper aims to investigating the effects of social media on the relationship between journalists and "produsers"-a hybrid combining the roles of producer and user adopted by news audiences in the Web 2.0 age. Based on a heuristic model of audience inclusion in journalism, this paper conducted a web survey of Taiwan's journalists and analyzed the interactive relationship that they had with their audience through various types of social media. The findings suggest that electronic media journalists and journalists with Facebook accounts that are open to the public are more inclined to interact with audience. Male journalists interact more with audience than female journalists. In addition, journalists who identify with public participation in the news and subsequently integrate audience outputs into their products and work routines, and those whose media use emphasizes audience involvement exhibit higher levels of audience interaction through their Facebook accounts. Finally, the results reveal that the accessibility of journalists' Facebook accounts to audience members is the most powerful variable in the journalists' interactions with audience.
\end{abstract}

\section{Keywords}

Produser, Collaborative Journalism, Inclusion Theory, Web 2.0 Culture, Social Media, News 2.0

\section{Introduction}

The development of the Web 2.0 culture has prompted revolutionary changes in the concept of "the audience".

How to cite this paper: Wang, T.-L. (2016). From News Receiver to News Produser-The New Relationship between Journalists and Audience in Web 2.0. Advances in Journalism and Communication, 4, 55-66. 
People can shape their own media use habits, create their own networks, and play the dual role of user and producer as "produsers" (Bruns, 2008). Under such circumstances, the central concept of the current study is how produsers interact with mainstream media and participate in the news production process.

In the initial phase of this study, social media became a new venue for communication. The relationship between social media and mainstream media has gained increasing academic attention. Before 2006, most journalists in Taiwan did not treat bloggers as competitors, or their social media as official communication channels or credible news sources (Tu, 2006). Mainstream media reporters only defined social media as "private space to share and express personal thoughts" or as "a way that the general public assumes to participate in public affairs". Therefore, social media were treated like private diaries that were unlikely to significantly influence the work of mainstream media reporters.

However, in the United States, Wall (2004) discovered that the mainstream media had grasped authority again in the Internet age through the use of social media. Singer (2005) argued that the ways in which mainstream journalists' use of social media might affect the traditional news style. Reporters who use social media have begun to integrate social media-specific writing styles into their traditional news writing routines. Robinson (2006) analyzed social media maintained by US journalists and found that social media use changed some of their journalistic ideas and norms. Although such reporters intended to maintain traditional news values, social media writing inevitably changed the essence of their journalistic practices.

There have also been subtle changes in the relationship between social media and the mainstream media. The latter often used to claim that social media could not challenge their dominant status in the news industry. However, the coverage of recent natural disasters across the world has rendered the relationship between traditional and new media both competitive and cooperative.

The purpose of this study is therefore to examine the changing relationship between journalists and audiences generated by social media use in the Web 2.0 era. It examines how journalists interact more active via social media. Do journalists really interact with audiences via social media? If so, in what ways do they interact with audience? What are the determining factors that influence journalists' perceptions of their audiences in the age of social media?

\section{Literature Review}

\subsection{The New Relationship between Journalist and Audience}

The vigorous development of the Web media has resulted in dramatic changes in the media production process, particularly during the Web 2.0 era. Jenkins (2006: pp. 2-4) used the term "convergence culture" to define the new era in which the media industries, news production, and news consumption converge. Participatory culture is an important element in the convergence process. Audience members gain access to news editing, production, and dissemination processes and become produsers- "a new kind of cultural power emerging as fans bond together within larger communities" and "pool their information, shape each other's opinions, and develop a greater self-consciousness about their shared agendas and common interests” (Jenkins, 2007: pp. 362-363). Produsers contribute to networked public spheres by filtering, commenting on, liking, retweeting, social media using, evaluating, and distributing information from various sources.

From an epistemological perspective, social media expands the communication space between journalist and audience in a subtle but important way by rebuilding the system through which knowledge is communicated, which creates a space shared by journalists and the audience. At the same time, the relationship between news professionals and audience members is also being redefined (Matheson, 2004).

Matheson (2004) investigated the effects that social media have on journalists' work, and pointed out that social media have transformed the news tradition from one with an abstract authority to one with a more situated authority. Network linking allows audience members to gain more diversified information from both traditional news workers and social media users. In this context, a text's meaning is more actively constructed by the audience because the diversity of the information may better reflect the perspectives of certain groups that have been neglected by the mainstream media for a long time. Such groups are now attracting the attention of particular audiences through the Internet.

Social media outlets also allow audience members to take the initiative in exploring, rather than just passively receiving, information. The vast nature of the Internet and its lack of hierarchical or organized features also give users access to previously unexpected information (Matheson, 2004). Thus, the relationship between news re- 
porters and news users becomes bidirectional and collaborative-a crowd sourcing model that leads to the appearance of unofficial news sources and amateur opinions (Bradshaw, 2008).

Therefore, this study first inquires how do social media affect the relationship between journalists and the audience via social media?

\subsection{Audience Inclusion Model in Journalism}

To inquire a newer potential relationship between journalists/media and the audience, this study adopts Loosen \& Schmidt's (2012) heuristic model of audience inclusion in journalism based on sociology inclusion theory (Luhmann, 1995) (see Figure 1).

Loosen \& Schmidt (2012) proposed two concepts to assess the symmetrical or asymmetrical relationships between journalism and the audience. First, the "inclusion level" refers to the inclusive performance between journalists and the audience. The second level is the "inclusion distance," which refers to expectations about journalism and audiences. Inclusion level and distance help clarify the complicated relationship between journalists and audience in the network media environment. This study focuses on the journalism side of this model (the left side of Figure 1) to investigate the changing relationship between journalists and the audience.

Journalistic inclusion performance can be assessed using three dimensions: the features of audience participation, the manifestation of audience participation in journalistic outputs, and journalists' work routines—all of which reproduce audience participation in news rooms.

The features of audience participation comprise different venues that media provide in which to interact with audiences, ranging from emails, social media, and discussion boards to Facebook accounts. The manifestation of audience participation can be measured by looking at the share of user-generated content among the news outputs, or at the frequency with which audience participation is mentioned and encouraged. Journalists' work routines include answering, aggregating, or forwarding audience feedback to the appropriate people in the news organizations. Thus, audience participation not only influences individual work routines, but also the institutional and organizational structure of journalism.

The inclusion expectations comprise three concepts: journalistic role conception, media strategic rationales, and images of the audience. Journalistic role conception comes from the concept of occupational socialization. An image of the audience is the audience's expectation of participating in the journalistic process. Media strategy rationale explains how media organizations allocate resources and make decisions involving the audience in the journalistic process.

\subsection{Journalists' Perceptions of Professional Roles}

Loosen and Schmidt's model represents a theoretical model delineating a newer relationship between journalists

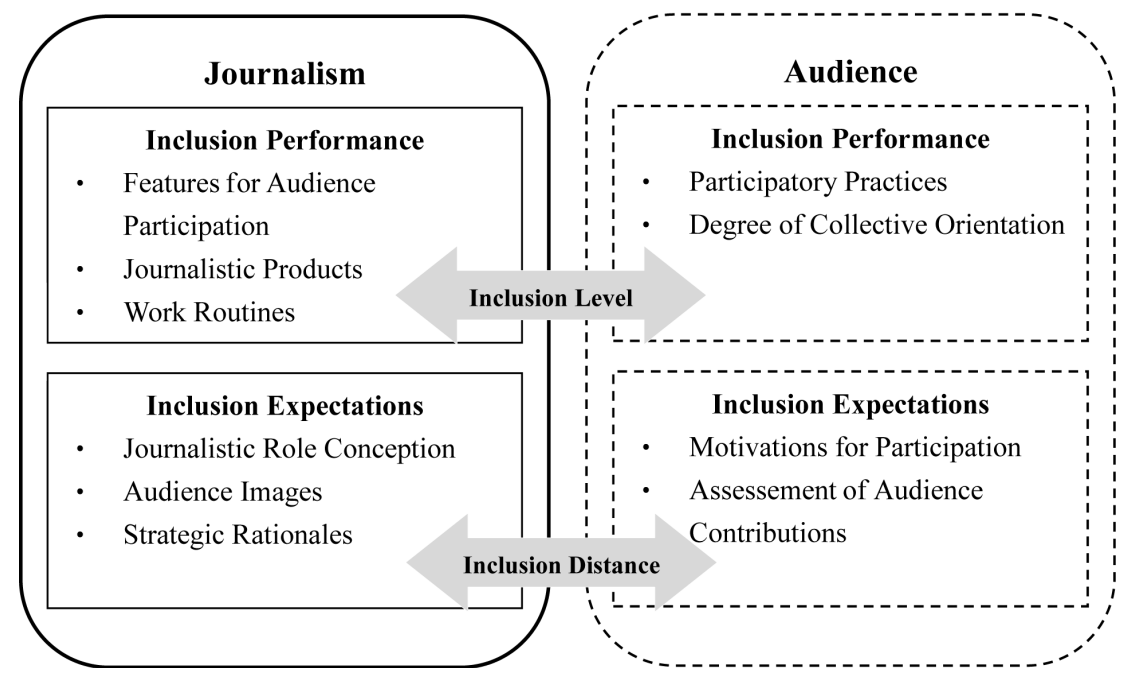

Figure 1. Analytical framework for audience inclusion in journalism. Source: Loosen \& Schmidt (2012). 
and audience. However, previous literature provides more operational definitions of critical concepts in this model, such as journalists' perception of professional roles, or journalistic role conception.

In its long-term development, media professionalism is considered to be the product of liberalism and is defined as supporting the professional practice of journalism norms (Lee, Chan, \& Lee, 1998).

Journalists expect different levels of participation from media professionals. According to Lee, Chan, \& Lee (1998), media professionals have certain features, including holding objectivity to be important, accessing information, providing entertainment, publicizing government policy, governmental supervision, and cultural cultivation.

So \& Chang (2007) explored news professionals in relation to journalists' perspectives on media function. For example, most journalists considered functions such as reporting the truth, providing immediate information, and analyzing complicated problems to be major requirements. The study also revealed journalists' attitudes toward the government, showing that they prefer to supervise government over taking a pro-government stance.

Hanitzsch et al. (2011) divided the news culture into three elements and seven domains to explore news professionals. The first element is the institutional role, which is divided into three domains: interventionism, distance of power, and market-orientation. The second element is epistemology, which is divided into two domains: objectivism and empiricism. The third element is ethical ideology, which is divided into two domains: relativism and idealism. In summary, journalists are regulated by the consensus of justice, objectivity, and precision.

Based on the literature, this study investigates journalists' perceptions of their role through six dimensions, including governmental supervision, objectivity, the provision of the information required by political decision-making, recommendations for daily life information, and the provision of entertainment or leisure information.

\section{Gender Issue and Online Interaction}

Survey results identified that $77.61 \%$ of the female users surfed the Internet, compared to $77.27 \%$ of male users do (Taiwan Network Information Center, 2013); that is, the gender differences in Internet use have equalized. However, U.S. studies specifically focused on reporters argued that male reporters still hold a more positive attitude toward and a higher interest in technology, which has resulted in increased familiarity and proficiency with technology compared with female reporters (Fallows, 2005).

A gender difference has also been identifiedin relation to social media use. Unlike female reporters, male reporters have been inclined to post public issues rather than personal experiences (Herring et al. 2004; Fredrick, 1999; Gao \& Martin-Kratzer, 2011; Pedersen \& Macafee, 2007). Moreover, gender has played an important role in social media use (Trammell \& Keshelashvili, 2005), with females exhibiting a much larger preference than males for engaging in self-exposure through social media.

For writing style on weblog, female reporters would tend to use diary form; male reporters prefer critical form, such as filter-blogs and knowledge-blogs (Herring et al., 2004; Herring \& Paolillo, 2006). Due to male reporters paid more attention to public issues on weblog content, male reporters' critical blogs were regarded as more influential and popular form than diary blogs (Herring \& Paolillo, 2006: p. 17). Female bloggers started dedicating to political issues more recently (Harp \& Tremayne, 2006).

According to another study surveying Asian reporters (Gao \& Martin-Kratzer, 2011), male reporters preferred hard issues and female preferred soft issues on blog writing, whereby blogs seemingly reproduced the traditionally gender differences in offline working field.

Moreover, gender plays an important role on the usage of blog (Trammell \& Keshelashvili, 2005); females prefer to do much more self-exposure, information disclosure and intimate interaction on blog than males (Trammell \& Keshelashvili, 2005; Bortree, 2005). However, Huffaker \& Calvert (2005) found that the frequency of discussion and self-exposure on adolescent bloggers did not have relation to gender differences. Therefore, whether gender influences the usage of blog still remains to be explored.

In terms of the blogsphere, by examining the interface and visual design on blog, a cross-cultural analysis of social media indicated that Wretch, one of the popular blog spaces in Taiwan, still exhibited high tendency of masculine culture, which emphasized on the traditionally institutionalized gender division labor, such as housework for female and occupation for male (Chang \& Tseng, 2009). That is, with implications by the design of blog, online space could reproduce offline ideology of gender labor division through the arrangement of online texts and images. 
Regarding online interactions, researchers have found that female journalists have a stronger need for interpersonal communication while male journalists are more motivated to seek information (Jackson, Ervin, Gardner, \& Schmitt, 2001: p. 374). Thus, female journalists operate on a higher level of online interaction. However, most journalists do not treat social media outlets such as social media as competitors or official communicating conduits; they regard them as spaces for expressing personal opinions. To disclose whether gender factors affect journalists' interactions with audience members through social media, this study further asks: Does journalists' gender affect their interactions with audience members?

\section{Collaborative Journalism in the Web 2.0 Era}

The development of Web 2.0 has turned social media platforms into important tools for transforming the mode of news production. Traditionally, the relationship between journalists and the audience has been regarded as a connection between sender and receiver. However, news production in the digital age, or "News 2.0", may prove significantly more collaborative in its involvement of news professionals and audience members.

"News 2.0" has brought certain structural changes in the journalism industries. Collaborative journalism is replacing traditional news reporting formats to produce text by multiple authors, allowing readers to participate by questioning, commenting, issuing peer-recommendations, subscribing to RSS feeds, or using bookmarks before publishing. The concept of collaborative media not only provides a new reporting format, but also the possibility of collaboration among institutes, individuals, and machines (Chattopadhyay, 2011).

Another similar concept, "crowdsourcing", was proposed by Howe (2006) and refers to the collaboration between news-related organizations and audience members. Collaborative journalism has blurred the traditional news classification, and many journalists have begun seeking collaboration with both journalism professionals and non-professionals (Chattopadhyay, 2011).

An increasing number of readerscan now use technological devices such as cameras, video equipment, and mobile phones to produce news content. In the future, new media applications and services will generate increased opportunities for news readers to participate in the creation of media products (Harrison \& Barthel, 2012).

Digital technology provides the possibility of practicing collaborative journalism. The central issue in applying the collaborative format in journalism is the journalists' attitudes toward the audience members' changing role as they become Web 2.0 co-creators. What do journalists think of user-generated content? Do journalists hold positive attitudes toward the audience's dual role as news receiver and producer? To explore these questions, a second line of questioning is proposed: Do journalists interact with audience members via social media? Do the media types matter to the interactions? What are the roles of journalists' gender during the interaction process? Finally, does the accessibility of journalists' social media have any influence on such the interaction?

All in all, this study proposes the following research questions.

(1) How do social media affect journalists' routines and news product outputs?

(2) How do journalists interact with audiences via social media in terms of media types, gender, and accessibility of social media?

(a) Do media types affect journalists' interactions with audience members?

(b) Does a journalist's gender influence his or her interaction with audience members?

(c) Does the accessibility of social media affect interactions between journalists and audience members?

(3) What factors influence journalists' interactions with audience members?

\section{Research Method}

An online survey was conducted to investigate the relationship between journalists and audience members via Facebook. Web surveys are considered an easier channel for reaching journalists who use social media. Although the purposive sample had a potential representativeness problem, given the purpose and needs of the research, a Web survey was deemed a feasible approach at this preliminary research stage.

A well-known Taiwanese Web survey platform was used to disseminate the questionnaires. The respondents were recruited from news department of television stations, newspaper, magazines, radio stations, and online media and independent media. The survey was administered from September 28 to October 12, 2011, and Feb.1 to Feb.14, 2013.The author sent 853 invitation letters via email with the Web survey link attached. Two hundred and forty complete surveys were ultimately collected, giving a response rate of $30 \%$. The questionnaire items 
were measured on a 7-point Likert scale ranging from 1 (strongly disagree) to 7 (strongly agree). After eliminating illegible or incomplete surveys, 213 surveys were entered into statistic analysis.

Due to the relatively limited literature on empirical studies of the relationship between journalists and audience members in the Web environment, this study develops concepts from the Audience Inclusion Model (Loosen \& Schmidt, 2012) and research on participatory or collaborative journalism (Matheson, 2004; Chattopadhyay, 2011; Wardle \& Williams, 2010).

This study measured six variables adopting from the inclusion theoretic model of journalists’ perspectives and include demographic variables. The variables were measured and defined as follows.

(1) Work routines: The level at which journalists used audience outputs in their work routines was assessed by the items "Using Facebook is a standardized tool of news production", "Facebook is very useful in an emergent situation”, "Facebook challenges my original news values”, "My colleagues all use Facebook”, "I always use Facebook to contact news sources", "I always use Facebook to post my reports", "I always use Facebook to share other's reports", "Facebook has changed the way I used to do drafts", "Facebook has changed my interview arrangement model”, and “Using Facebook can enhance the reporting of emergent news”. The Cronbach’s $\alpha$ was 0.793 .

(2) Media strategy rationale: Strategy refers to the effect of the internal allocation of media organizations' resources and decision-making networks or social networking sites. The assessed items were "The use of social media, like Facebook, facilitates the level of audiences' dependence on media”, "News media where I work use social media, like Fans pages, to interact with audiences”, "Internet use creates new journalism jobs”, "Using social media can enlarge the influence of news", and "Through social media, I can report the news that traditional media cannot report”. The Cronbach’s $\alpha$ was 0.784 .

(3) Public participation: Journalists' perception of public participation in news was assessed by the items "Social media give audiences the ability to participate in news production”, “Audience members' participation through social media can improve news quality", "Social media can enlarge the public participation of audiences", "The use of Internet empowers audience members in the process of receiving news", and "I can access audience members’ opinions on public issues through social media”. The Cronbach’s $\alpha$ was 0.802 .

(4) Journalistic role conception: Journalists' perception of their professional role was assessed by items such as "My role is to supervise the government”, "I keep objective in my reporting”, "My job is to provide the information for audience members' political decision making”, "My job is to provide information, suggestions, and guidance for audiences in daily life”, and “My report can entertain audiences”. The Cronbach's $\alpha$ was 0.700 .

(5) Journalistic products/outputs: The level at which journalists incorporate audience outputs into their products was assessed by the items "I always use Facebook to search for news sources", "I use Facebook for new ideas and creativity in my job”, "Using Facebook has become a daily channel for receiving information”, "I use Facebook to contact my colleagues”, and “I use Facebook to access instant messages”. The Cronbach's $\alpha$ was 0.818 .

(6) Audience interaction: Journalists' interactions with audience members were measured by items such as "Facebook improves the scarcity of traditional news reporting”, "Using Facebook makes me more aware of audience-centered values", "I use my social media site to interact with audience members", "I use social media to access audience members' evaluations of news reports”, and "I use social media sites to learn what audience members care about”. The Cronbach's $\alpha$ was 0.781 .

(7) Demographics: The demographic variables included age, gender, work experience, and education.

A reliability analysis was used to examine the validity of the questionnaire. Thirty-five items were examined, with Cronbach's $\alpha$ values ranging from 0.702 to 0.818 and an average of 0.807 . The KMO values ranged from 0.737 to 0.816 and the Bartlett test value was significant $(p<0.001)$. Therefore, all of the items were suitable for factor analysis. Principal component analysis and Varimax rotation were used for the factor analysis. Table 1 indicates the findings. The explained variances of each factor were between $53.97 \%$ and $63.54 \%$.

\section{Results}

First of all, a hierarchical regression analysis was conducted to investigate the importance of each factor contributing to journalists' interactions with audience members through Facebook (Table 2). Given that the purpose of this study is to investigate the relationship between journalists and audience members, the factors of the journalism inclusion model (Loosen \& Schmidt, 2012) were grouped into block one. Then, the journalists’ media types and social media use were grouped into block two because they can be influenced by journalistic inclusion. 
Table 1. Factor analysis of the variables.

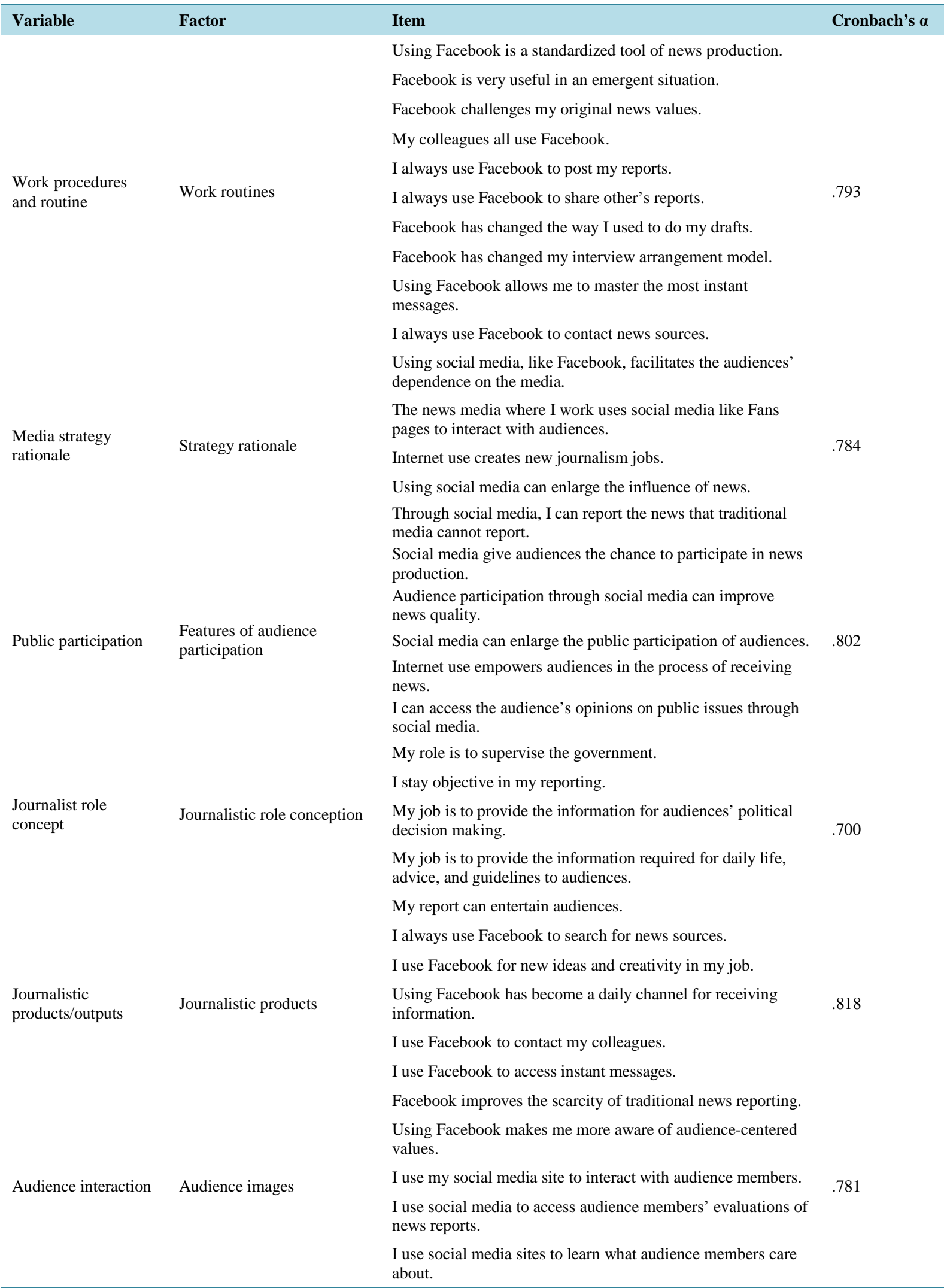


Table 2. Multiple regression of potential factors influencing journalist and audience interaction via Facebook.

\begin{tabular}{|c|c|c|c|}
\hline \multirow{2}{*}{ Independent variable } & \multicolumn{3}{|c|}{ Regression } \\
\hline & 1 & 2 & 3 \\
\hline \multicolumn{4}{|l|}{ Block 1: } \\
\hline Public participation & $.39 * * *$ & $.24^{* *}$ & $.25^{* *}$ \\
\hline Journalist products & .11 & $.20^{*}$ & $.19 *$ \\
\hline Work routines & .15 & .06 & .07 \\
\hline Media strategy rationale & .08 & .13 & .14 \\
\hline Journalist role concept & .11 & .04 & .04 \\
\hline \multicolumn{4}{|l|}{ Block 2: } \\
\hline Media type & & .11 & .11 \\
\hline Accessibility of Facebook & & $.33^{* * *}$ & $.31^{* * *}$ \\
\hline \multicolumn{4}{|l|}{ Block 3: } \\
\hline Age & & & .06 \\
\hline Gender & & & -.07 \\
\hline Work experience & & & -.06 \\
\hline Education & & & -.06 \\
\hline Multiple R & .42 & .53 & .54 \\
\hline Adjusted R square & .40 & .51 & .51 \\
\hline Increased R square & .42 & .12 & .007 \\
\hline
\end{tabular}

Note: The beta weights are from the final regression analysis that included all of the variables in the model $(\mathrm{n}=213) . * * * \mathrm{p}<.001,{ }^{* *} \mathrm{p}<.01,{ }^{*} \mathrm{p}$ $<.05$.

The demographic factors were grouped into block three.

In the first block of the regression analysis (column 1), the variables entered were public participation, journalist role concept, journalist products, media strategy, and journalists' work routines. In the second block, the variables for media types and social media accessibility were added (column 2). The final block included the demographic variables of age, gender, work experience, and education level (column 3).

The results revealed that the accessibility of journalists' Facebook accounts to audience members was the most powerful variable $(~(=.31, \mathrm{p}<.001)$, followed by public participation $(\Omega=.25, \mathrm{p}<.01$ ). Journalist products emerged as the third most significant factor $(ß=.19, \mathrm{p}<.05)$. Journalist roles, work routine, media strategies, media types, and the demographics of age, gender, work experience, and education were found to be insignificant factors.

The adjusted multiple correlation was $\mathrm{R}=.51$, indicating that $51 \%$ of the variance was explained by these variables.

Regarding journalists' perceptions of how public participation, their professional roles, and their work routines and media strategies affect their interactions with audience members, the Pearson's correlation revealed that journalists' audience interaction was positively correlated to their perceptions of public participation in the news $(\mathrm{r}=6.00, \mathrm{p}<.001)$, journalistic products/outputs $(\mathrm{r}=.488, \mathrm{p}<.001)$, work routines $(\mathrm{r}=.471, \mathrm{p}<.001)$, media strategy rationale $(r=.470, p<.001)$, and perceptions of professional roles $(r=.219, p<.01)$ (Table 3). The result imply that journalists who identified more with public participation in the news, those who integrated audience members' outputs into their products and work routines, and those whose media emphasized audience involvement strategies had higher levels of audience interaction via their Facebook use.

Regarding whether different types of media influence the interactions between journalists and audience members and the effects of journalists' gender and social media accessibility, the t test results showed that the electronic media journalists tended to have higher levels of interaction with audience members than those in the print media (Table 4) (electronic media $=5.00$, print media $=4.60, \mathrm{p}<.05$ ). The electronic media journalists were more likely to use Facebook to understand audience members' values, interact with audience members, review how audience members comment on their reports, and understand what issues are important to audience members. 
Table 3. Correlations between audience interaction and perceptions of public participation, journalists' roles, journalistic outputs, work routines, and media strategies.

\begin{tabular}{cc}
\hline & Audience Interaction \\
\cline { 2 - 2 } Public participation & Pearson's r \\
Journalistic products/outputs & $.600^{* * *}$ \\
Work routines & $.488^{* * *}$ \\
Media strategy rationale & $.471^{* * *}$ \\
Journalistic role conception & $.470^{* * *}$ \\
\hline
\end{tabular}

${ }^{* * *} \mathrm{p}<.001,{ }^{* *} \mathrm{p}<.01,{ }^{*} \mathrm{p}<.05$

Table 4. Interactions between journalists and audience members via Facebook.

\begin{tabular}{|c|c|c|c|c|c|}
\hline \multicolumn{6}{|c|}{ Type of media and audience interaction via Facebook } \\
\hline & \multicolumn{2}{|c|}{$\begin{array}{l}\text { Print media } \\
(\mathrm{N}=105)\end{array}$} & \multicolumn{3}{|c|}{$\begin{array}{l}\text { Electronic media } \\
(\mathrm{N}=108)\end{array}$} \\
\hline & Mean & Std. Deviation & Mean & Std. deviation & t-value \\
\hline Audience interaction & 4.60 & 1.03 & 5.00 & .84 & $-2.702 * *$ \\
\hline \multicolumn{6}{|c|}{ Gender and audience interaction via Facebook } \\
\hline & $\begin{array}{l}\text { Male } \\
(\mathrm{N}=77)\end{array}$ & & $\begin{array}{l}\text { Female } \\
(\mathrm{N}=136)\end{array}$ & & \\
\hline & Mean & Std. Deviation & Mean & Std. deviation & t-value \\
\hline Audience interaction & 5.10 & 1.02 & 4.64 & .88 & $2.959 * *$ \\
\hline \multicolumn{6}{|c|}{ Facebook accessibility and audience interaction via Facebook } \\
\hline & $\begin{array}{l}\text { Private } \\
(\mathrm{N}=113)\end{array}$ & & $\begin{array}{l}\text { Public } \\
(\mathrm{N}=100)\end{array}$ & & \\
\hline & Mean & Std. deviation & Mean & Std. deviation & $\mathrm{t}$-value \\
\hline Audience interaction & 4.36 & 0.91 & 5.32 & .72 & $-7.485^{* * *}$ \\
\hline
\end{tabular}

${ }^{* * *} \mathrm{p}<.001,{ }^{* *} \mathrm{p}<.01,{ }^{*} \mathrm{p}<.05$.

Male journalists were found to interact more with audience members than their female counterparts (male $=$ 5.10, female $=4.64, \mathrm{p}<.05$ ). Finally, journalists with Facebook accounts that were open to the public interacted more with audience members than journalists with private accounts (public $=5.32$, private $=4.3, p<.001$ ).

\section{Discussion}

The growing popularity of social media has contributed to the transformation of journalism, which has gradually developed into a new type of interaction between journalists and audience members. To explore this emerging relationship, based on the inclusion model, this study investigated journalists' news production behavior and their perceptions of the audience.

The results also reveal that journalists with higher levels of audience interaction through their Facebook accounts identified more with public participation in the news, integrated more audience outputs into their products and work routines, and emphasized audience involvement strategies. The interactions between journalists and audience members, which are affected by inclusive performance, can be displayed in news production. Journalists look to social media for news resources that will help them grab the audience's attention, especially when the news content provided by a non-professional produser is much more interesting. From another perspective, audience participation is becoming part of professional routines and industrial structures. Collaborative journalism actually urges journalists to seek new voices, which encourages the possibility of cooperation among institutes, individuals, and machines (Chattopadhyay, 2011).

According to the current findings, audience members' access to journalists' Facebook accounts was the most powerful factor contributing to journalists' interactions with audience members through Facebook; followed by public participation and journalist products, respectively. This suggests that journalists' perceptions of audience 
members are changing. Audiences are no longer exclusively passive receivers, but collaborators in news production. Journalists have become much more dependent on audience members than they were in traditional journalism. The forms of traditional news reporting are being gradually replaced by collaborative journalism, which allows audience participation.

Through Facebook, journalists can access immediate feedback provided by "active” audience members who represent the civic voice. As Bradshaw (2008) noted, the relationship between news producers and users becomes bidirectional, with their collaboration leading to the more frequent appearance of unofficial sources or amateur opinions in the news. In these circumstances, whether journalists can remain discerning enough to examine sources or become easily swayed by public desires remains a question.

Especially for electronic journalists working in Web 2.0, the purpose of using social media is to engage audience members in the news production process. Conforming to public opinion, in a sense, is an approach to ensuring ratings. Therefore, commercialism may become one of the forces urging journalists to use social media and interact with audience members. As Chattopadhyay (2011) noted, the highly commercialized and institutionalized communicative approach may become another way to institutionalize. Moreover, some journalists may interact with audiences via social media to become famous or gain public influence. This study observed the trend that journalists in Taiwan have different strategies for using social media. Facebook, unlike social mediaging, is regarded as a channel for communicating with audience members rather than as a private space for personal sharing.

Furthermore, the results suggest that male journalists interact more with audience members through Facebook than their female counterparts. This phenomenon corresponds to previous findings that gender is a factor that affects journalists' use of social media, which further influences their interactions with audience members (Weiser, 2000: p. 175; Jackson, Ervin, Gardner, \& Schmitt, 2001: p. 374). Female journalists tend to regard Facebook as a private social network rather than as a tool for career influence. Moreover, the conservative attitudes of female journalists toward Facebook may be the result of safety concerns. In fact, female tend to encounter more online harassment than male (Hess, 2014). According to Chawki \& Shazly (2013), social media provide online users to communicate via updating status, posting messages on personal 'walls' or instant private messaging, and to connect with old or new friends online. However, it may cause online harassment including stalking or bullying (Chawki \& Shazly, 2013). For example, a female journalist was harassed by online fans and caused her to suffer psychological trauma (Liu, Chao, Hu, \& Hsieh, 2012).

In regards to the differences between electronic and print media, the results indicate that electronic media journalists tend to interact more with audience members through Facebook compared with print media journalists. Likewise, journalists with public Facebook accounts interact more with audience members than journalists with private Facebook accounts.

Electronic media journalists have online video and audio files ready for spontaneous dissemination, whereas print media journalists may be less likely to disseminate their reporting in electronic forms in real time. The features of Web 2.0 media may correspond more to electronic media journalists, who require more video and audio resources as news material or online sharing content. Meanwhile, when electronic media journalists use Facebook to interact with audience members or to explore issues that are important to audiences, they are actually in closer contact with public opinion. The reason why electronic media's journalists regarded audience's opinion as more important index for news content selection may be related to commercial media system in Taiwan.

As pointed out by Turner (2014), the highly competitive media market nowadays lead news organizations to emphasize entertaining rather than informative content, and visuals than texts. In Taiwan, in order to attract audience, one of the strategies adopted by electronic media companies is to recruit reporters with "good looking faces”. Company policies also encourage news reporters or announcers to actively manage social media to interact more with audiences. On the contrary, for print media reporters, they do not shoulder the immediate rating pressure as electronic reporters; hence have less emergency of interacting with audiences. This could be one of possible reasons why electronic media reporters have more interaction with audiences than print media journalists.

Another possibility may stem from “fame economics” (Lin, 2006). Lin (2006) argued that journalists' "habitus psychology” and market mechanism make "fame” a significant commodity in today's journalism industry. In Taiwan, after martial law, electronic journalists are particularly interested in drawing print media's attention, becoming “celebrity”, and building fame to accumulate personal assets through "commodity appearances”. 
Among all, young electronic journalists are more aggressively to increase their fame and popularity by exposing on news coverage, and share those coverage immediately on their social media to increase fans' views or likes.

Such "fame economics" establishes a new market's habitus, and the following marketing commodity production strategies, which may further strengthen electronic journalists' motivations to interact more with audience on social media.

In regard to research limitation of this study, though this study investigated the interactions between journalists and audience members through social media, some research limitations must be addressed. With the development of social media, the interactions between Facebook users continue to change, especially how one "follows" or "likes" a page. This study did not explore these changes, but future studies could consider their influence on the relationship between journalists and audience members. One another research limitation is that this study's sample is not a random sample of the whole population of Taiwan's journalists. The generalization of research results will need to be cautious.

\section{Acknowledgements}

This work was supported by the Ministry of Science and Technology under Grant 99-2410-H-002-163.

\section{References}

Bortree, D. S. (2005). Presentation of Self on the Web: An Ethnographic Study of Teenage Girls' Weblogs. Education, Communication and Information, 5, 25-39.

Bradshaw, P. (2008). Social Mediaging Journalists: Survey Results. http://onlinejournalismblog.com/2008/10/14/blogging-journalists-survey-results-pt1-context-and-methodology/

Bruns, A. (2008). Social Medias, Wikipedia, Second Life, and Beyond: From Production to Produsage (Vol. 45). New York: Peter Lang.

Chang, H.-J., \& Tseng, I.-C. (2009). A Cross-Cultural Analysis of Social Network Sites in Taiwan and USA: A Comparison Between Wretch and My Space. Journal of Electronic Business, 11, 611-638.

Chattopadhyay, S. (2011). Collaborative Journalism: Networks, News Media and the Public Sphere. In K. Malik, \& P. Choudhary (Eds.), Business Organizations and Collaborative Web: Practices, Strategies and Patterns (pp. 48-60). Hershey, PA: IGI Global.

Chawki, M., \& Shazly, Y. (2013). Online Sexual Harassment. Journal of Intellectual Property, Information Technology, and E-commerce Law, 4, 71-86.

Fallows, D. (2005). How Women and Men Use the Internet. Pew Internet and American Life Project 28.

Fredrick, C. A. N. (1999). Feminist Rhetoric in Cyberspace: The Ethos of Feminist Usenet Newsgroups. Information Society, 15, 187-197.

Gao, F. F., \& Martin-Kratzer, Re. (2011). Gender Differences in Chinese Journalists' Social Medias. Chinese Journal of Communication, 4, 167-181.

Hanitzsch, T., Hanusch, F., Mellado, C. et al. (2011). Mapping Journalism Cultures across Nations: A Comparative Study of 18 Countries. Journalism Studies, 12, 273-293.

Harp, D., \& Tremayne, M. (2006). The Gendered Blogosphere: Examining Inequality Using Network and Feminist Theory. Journalism \& Mass Communication Quarterly, 83, 247-264.

Harrison, T. M., \& Barthel, B. (2012). Wielding New Media in Web 2.0: Exploring the History of Engagement with the Collaborative Construction of Media Products. New Media and Society, 11,155-178.

Herring, S. C., \& Paolillo, J. C. (2006). Gender and Genre Variation in Weblogs. Journal of Sociolinguistics, 10, 439-459.

Herring, S. C., Scheidt, L. A., Bonus, S., \& Wright, E. (2004). Bridging the Gap: A Genre Analysis of Weblogs. 2004 Proceedings of the 37th Annual Hawaii International Conference on System Sciences, Hawaii, 5-8 January 2004, 11.

Hess, A. (2014). Why Women Aren’t Welcome on the Internet. Pacific Standard. http://www.psmag.com/navigation/health-and-behavior/women-arent-welcome-internet-72170/

Howe, J. (2006). The Rise of Crowdsourcing. Wired, 14. http://www.wired.com/wired/archive/14.06/crowds.html

Huffaker, D. A., \& Calvert, S. L. (2005). Gender, Identity, and Language Use in Teenage Blogs. Journal of Computer-Mediated Communication, 10. http://dx.doi.org/10.1111/j.1083-6101.2005.tb00238.x

Jackson, L. A., Ervin, K. S., Gardner, P. D., \& Schmitt, N. (2001). Gender and the Internet: Women Communicating and Men Searching. Sex Roles, 44, 363-379. http://dx.doi.org/10.1023/A:1010937901821 
Jenkins, H. (2006). Convergence Culture: Where Old and New Media Collide. New York: New York University Press.

Jenkins, H. (2007). Afterword: The Future of Fandom. In C. Sandvoss, C. L. Harrington, \& J. Gray (Eds.), Fandom: Identities and Communities in a Mediated World (pp. 357-364). New York: New York University Press.

Lee, C.-C., Chan, J. M., \& Lee, S. N. (1998). Professionalism among Hong Kong Journalists in Comparative Perspective. In B. McIntrye (Ed.), Mass Media in the Asian Pacific (pp. 5-13). Clevedon: Multilingual Matters Ltd.

Lin, F.-M. (2006). When Newsmen Become Critics: Inquiry of Fame, Profession and Labor Commodification. Mass Communication Research, 88, 43-81. (In Chinese)

Liu, L.-J., Chao, J.-Y., Hu, C.-H., \& Hsieh, W.-H. (2012). The Side Effect of Media Monopoly Results in the Wave of Resignation in China Times. http://www.libertytimes.com.tw/2012/new/aug/10/today-life1.htm

Loosen, W., \& Schmidt, J.-H. (2012). (Re-)discovering the Audience: The Relationship between Journalism and Audience in Networked Digital Media. Information, Communication and Society, 15, 867-887. http://dx.doi.org/10.1080/1369118X.2012.665467

Luhmann, N. (1995). Social Systems. Redwood City, CA: Stanford University Press.

Matheson, D. (2004). Weblogs and the Epistemology of the News: Some Trends in Online Journalism. New Media and Society, 6, 443-468. http://dx.doi.org/10.1177/146144804044329

Pedersen, S., \& Macafee, C. (2007). Gender Differences in British Blogging. Journal of Computer-Mediated Communication, 12, 1472-1492. http://dx.doi.org/10.1111/j.1083-6101.2007.00382.x

Robinson, S. (2006). The Mission of the j-Blog: Recapturing Journalistic Authority Online. Journalism, 7, 65-83. http://dx.doi.org/10.1177/1464884906059428

Singer, J. B. (2005). The Political j-Blogger: “Normalizing” a New Media Form to Fit Old Norms and Practices. Journalism, 6, 173-198. http://dx.doi.org/10.1177/1464884905051009

So, C. Y. K., \& Chan, J. M. (2007). Professionalism, Politics and Market Force: Survey Studies of Hong Kong Journalists 1996-2006. Asian Journal of Communication, 17, 148-158. http://dx.doi.org/10.1080/01292980701306506

Taiwan Network Information Center (2013). The Report of the Wireless Internet Usage in Taiwan. http://www.twnic.net.tw/download/200307/20140109d.pdf

Trammell, K. D., \& Keshelashvili, A. (2005). Examining the New Influencers: A Self-Presentation Study of A-List Blogs. Journalism and Mass Communication Quarterly, 82, 968-982. http://dx.doi.org/10.1177/107769900508200413

Tu, N.-L. (2006). The Impact of Blogs on Newspaper Journalists’ Behavior. Master Thesis, Taipei: Department of Journalism, Shih Hsin University.

Turner, G. (2014). Is Celebrity News, News? Journalism, 15, 144-152.

Wall, M. (2004). Social Medias as Black Market Journalism: A New Paradigm for News. Interface on the Internet, 4, No. 2. http://commons.pacificu.edu/cgi/viewcontent.cgi?article=1007\&context=inter04

Wardle, C., \& Williams, A. (2010). Beyond User-Generated Content: A Production Study Examining the Ways in Which UGC Is Used at the BBC. Media, Culture and Society, 32, 781-799. http://dx.doi.org/10.1177/0163443710373953

Weiser, E. B. (2000). Gender Differences in Internet Use Patterns and Internet Application Preferences: A Two-Sample Comparison. Cyber Psychology and Behavior, 3, 167-178. http://dx.doi.org/10.1089/109493100316012 